\title{
Optimization of phenolics and flavonoids extraction conditions of Curcuma Zedoaria leaves using response surface methodology
}

\author{
Nur Fauwizah Azahar ${ }^{1,2}$, Siti Salwa Abd Gani ${ }^{1,2^{*}}$ and Nor Fadzillah Mohd Mokhtar ${ }^{2,3}$
}

\begin{abstract}
This study focused on maximizing the extraction yield of total phenolics and flavonoids from Curcuma Zedoaria leaves as a function of time (80-120 $\mathrm{min})$, temperature $\left(60-80^{\circ} \mathrm{C}\right)$ and ethanol concentration $(70-90 \mathrm{v} / \mathrm{v} \%)$. The data were subjected to response surface methodology (RSM) and the results showed that the polynomial equations for all models were significant, did not show lack of fit, and presented adjusted determination coefficients $\left(R^{2}\right)$ above $99 \%$, proving their suitability for prediction purposes. Using desirability function, the optimum operating conditions to attain a higher extraction of phenolics and flavonoids was found to be $75^{\circ} \mathrm{C}, 92 \mathrm{~min}$ of extraction time and 90:10 of ethanol concentration ratios. Under these optimal conditions, the experimental values for total phenolics and flavonoids of Curcuma zedoaria leaves were $125.75 \pm 0.17 \mathrm{mg}$ of gallic acid equivalents and $6.12 \pm 0.23 \mathrm{mg}$ quercetin $/ \mathrm{g}$ of extract, which closely agreed with the predicted values. Besides, in this study, the leaves from Curcuma zedoaria could be considered to have the strong antioxidative ability and can be used in various cosmeceuticals or medicinal applications.
\end{abstract}

Keywords: Curcuma zedoaria, Antioxidant activity, Response surface methodology, Phenolic, Flavonoids

\section{Background}

Plants are a substantial source of natural antioxidants. Active compounds present in natural antioxidants such as phenolic, carotenoids, flavonoids, folic acid, benzoic acid, and tocopherol are secondary metabolites of the plants which can provide various potential treatment and prevention of cancer, cardiovascular diseases, neurodegenerative diseases and etc. $[1,2]$.

Phenolics or polyphenols, including flavonoids, have received greater attention because they are often identified as biological response modifiers and have various functions such as metal chelators and free radical terminators $[3,4]$. The bioactive compounds present in these compounds provide a variety of physiological functions, for instance, antimicrobial, antiallergenic,

\footnotetext{
*Correspondence: ssalwaag@upm.edu.my; ssalwa.abdgani@gmail.com ${ }^{1}$ Department of Agriculture Technology, Faculty of Agriculture, Universiti Putra Malaysia (UPM), 43400 Serdang, Selangor, Malaysia

Full list of author information is available at the end of the article
}

anti-inflammatory, and antimutagenic effects [5]. Moreover, it has been reported that the active compounds found in phenolic acids (caffeic, chlorogenic acid, benzoic acid) and flavonoids (catechin, quercetin, rutin) are potent antioxidants because they have all the right structural features for free radical scavenging activity $[6,7]$.

Curcuma zedoaria (Christm.) Roscoe. from Zingiberaceae family is popularly known as white turmeric, zedoaria or gajutsu [8]. This medicinal herb is largely found in East-Asian countries including Malaysia, Indonesia, China, India, Japan, Vietnam and Bangladesh [9]. Traditionally, zedoaria is hugely consumed as a spice, a flavoring agent, a tonic, a treatment for menstrual disorders, vomiting, toothache and it is also made into perfume [10, 11]. A study done by Angel et al. [12] reveals that zedoaria plants have a certain camphoraceous aroma and enormous functional active compounds such as essential oils, phenolics, and flavonoids which are strong components of anti-oxidant agent [12]. Meanwhile, Srivastava et al. [13] reported that Curcuma zedoaria 
is closely related to Curcuma longa. Therefore, the correlative isolated active compounds found in zedoaria such as curcumin, demethoxycurcumin and bisdemethoxycurcumin could be effectively used as antioxidant and anti-inflammatory, similar to Curcuma longa which is popularly used as antioxidant, antiulcer, anti-inflammatory, etc. Moreover, in vivo studies reported that the rhizomes of the plant possess potent antioxidant activity which exhibited higher radical scavenging activity [14].

The extraction of antioxidant compounds is a crucial process to determine the quantity and type of bioactive compounds, each with different therapeutic properties that will be extracted out. According to Aybastier et al. [15] many factors contribute to the efficiency of extractions such as the type of solvent, the concentration of solvent, temperature, time, $\mathrm{pH}$ and solid-liquid ratios. Response surface methodology (RSM) is a powerful mathematical technique being widely used in many industries for technological operations to optimize the experimental conditions. RSM is also useful to maximize or minimize various independent variables as it evaluates the effects of multiple factors and their respective interactions on one or more response variables simultaneously. Besides, RSM not only serves as a visual aid to have a clearer picture about the effects of various factors on extraction but also helps to locate the region where the extraction is optimized.
Therefore, the optimum extraction conditions (time, temperature and solvent ratio) to obtain the highest amount of phenolic and flavonoid compounds from Curcuma zedoaria leaves was identified using RSM technique. Despite numerous studies on rhizomes of zedoary which investigated its antioxidant activity, the leaves of the plant literally have not gained enough recognition and study to the best of our knowledge. In addition, Chanda and Nagani [16] reported that leaves, in general, are selected for the evaluation of total antioxidants activity due to high content of bioactive compounds.

\section{Results and discussion}

Fitting the response surface models

A full factorial, central composite design (CCD) was used to identify the relationship between the response functions and process variables as well as to find out the conditions that optimized the extraction process. The experimental design and corresponding three response variables are presented in Table 1 . In the present study, according to the sequential model sum of squares, the highest order polynomials were utilized to select the models where the additional coefficients estimates were significant and the models are not aliased. Hence, for all three independent variables and responses, a quadratic polynomial model was selected and fitted well as suggested by the software.

Table 1 The experimental data obtained for the three responses based on the CCD matrix

\begin{tabular}{|c|c|c|c|c|c|c|}
\hline Run no & Type & Temperature $\left(X_{1}\right)$ & Time $\left(X_{2}\right)$ & Solvent ratio $\left(X_{3}\right)$ & $\begin{array}{l}\text { Phenolic } \\
\text { content } \mathrm{mg} / \mathrm{g} \text { GAE }\end{array}$ & $\begin{array}{l}\text { Flavonoid content } \\
\mathrm{mg} \text { QE/g extract }\end{array}$ \\
\hline 1 & Fact & 80.0 & 80.0 & 90.0 & 131.96 & 6.18 \\
\hline 2 & Fact & 60.0 & 120.0 & 70.0 & 116.76 & 6.00 \\
\hline 3 & Center & 70.0 & 100.0 & 80.0 & 122.20 & 6.24 \\
\hline 4 & Fact & 80.0 & 120.0 & 70.0 & 122.90 & 6.07 \\
\hline 5 & Axial & 53.18 & 100.0 & 80.0 & 116.14 & 6.09 \\
\hline 6 & Center & 70.0 & 100.0 & 80.0 & 122.64 & 6.23 \\
\hline 7 & Axial & 70.0 & 66.36 & 80.0 & 115.32 & 6.31 \\
\hline 8 & Axial & 86.82 & 100.0 & 80.0 & 135.77 & 6.05 \\
\hline 9 & Axial & 70.0 & 100.0 & 96.82 & 119.17 & 6.35 \\
\hline 10 & Fact & 80.0 & 80.0 & 70.0 & 121.80 & 6.21 \\
\hline 11 & Axial & 70.0 & 100.0 & 63.18 & 105.10 & 6.06 \\
\hline 12 & Fact & 80.0 & 120.0 & 90.0 & 122.43 & 6.22 \\
\hline 13 & Fact & 60.0 & 80.0 & 70.0 & 98.76 & 6.08 \\
\hline 14 & Fact & 60.0 & 80.0 & 90.0 & 115.83 & 6.33 \\
\hline 15 & Center & 70.0 & 100.0 & 80.0 & 122.32 & 6.23 \\
\hline 16 & Center & 70.0 & 100.0 & 80.0 & 122.24 & 6.21 \\
\hline 17 & Fact & 60.0 & 120.0 & 90.0 & 122.30 & 6.38 \\
\hline 18 & Axial & 70.0 & 133.64 & 80.0 & 122.27 & 6.26 \\
\hline 19 & Center & 70.0 & 100.0 & 80.0 & 122.55 & 6.22 \\
\hline 20 & Center & 70.0 & 100.0 & 80.0 & 122.25 & 6.23 \\
\hline
\end{tabular}


The final empirical regression model of their relationship between responses and the three tested variables for phenolic and flavonoid contents could be expressed by the following quadratic polynomial equation [Eqs. (1-2)]:

$$
\begin{aligned}
\text { Phenolic content }= & 122.36+5.74 X_{1}+2.03 X_{2}+4.10 X_{3} \\
& -4.11 X_{1} X_{2}-1.62 X_{1} X_{3}-2.77 X_{2} X_{3} \\
& +1.34 X_{1}^{2}-1.19 X_{2}^{2}-3.55 X_{3}^{2}
\end{aligned}
$$

$$
\begin{aligned}
\text { Flavonoid content }= & 6.23-0.013 X_{1}-0.016 X_{2}+0.091 X_{3} \\
& -0.08 X_{1} X_{2}-0.064 X_{1} X_{3}+0.039 X_{2} X_{3} \\
& \times 0.05 X_{1}^{2}+0.021 X_{2}^{2}-0.070 X_{3}^{2}
\end{aligned}
$$

where $X_{1}$ is the temperature, $X_{2}$ is the time and $X_{3}$ is the ethanol concentration ratio. A negative sign in each equation represents an antagonistic effect of the variables and a positive sign represents a synergistic effect of the variables.

The RSM model coefficients were validated by analysis of variance (ANOVA) of the response variables for the quadratic polynomial model summarized in Table 2 . The ANOVA results were calculated based on $95 \%$ confidence

\begin{tabular}{|c|c|c|c|c|c|}
\hline Sources & Sum of squares & Degree of freedom & Mean squares & F-value & $p$-value \\
\hline \multicolumn{6}{|c|}{ Phenolic content (mg/g GAE) } \\
\hline Model & 1191.21 & 9 & 132.36 & 1662.76 & $<0.0001$ \\
\hline$X_{1}$-temperature & 450.69 & 1 & 450.69 & 5661.84 & $<0.0001$ \\
\hline$x_{2}$-Time & 56.30 & 1 & 56.30 & 707.27 & $<0.0001$ \\
\hline$X_{3}$-solvent ratio & 229.32 & 1 & 229.32 & 2880.92 & $<0.0001$ \\
\hline$x_{1} x_{2}$ & 135.30 & 1 & 135.30 & 1699.75 & $<0.0001$ \\
\hline$x_{1} x_{3}$ & 20.87 & 1 & 20.87 & 262.13 & $<0.0001$ \\
\hline$x_{2} x_{3}$ & 61.38 & 1 & 61.38 & 771.14 & $<0.0001$ \\
\hline$X_{1}^{2}$ & 25.87 & 1 & 25.87 & 325.02 & $<0.0001$ \\
\hline$x_{2}^{2}$ & 20.46 & 1 & 20.46 & 257.06 & $<0.0001$ \\
\hline$x_{3}^{2}$ & 181.23 & 1 & 181.23 & 2276.79 & $<0.0001$ \\
\hline Residual & 0.80 & 10 & 0.080 & & \\
\hline Lack of fit & 0.63 & 5 & 0.13 & 3.74 & 0.0870 \\
\hline Pure error & 0.17 & 5 & 0.034 & & \\
\hline Cor total & 1192.01 & 19 & & & \\
\hline \multicolumn{6}{|l|}{$\begin{array}{l}R^{2}=0.9993 \\
\text { Adj. } R^{2}=0.9987 \\
\text { CV\% }=0.24\end{array}$} \\
\hline \multicolumn{6}{|c|}{ Flavonoid content (mg QE/g of extract) } \\
\hline Model & 0.22 & 9 & 0.024 & 229.66 & $<0.0001$ \\
\hline$X_{1}$-temperature & 0.002 & 1 & 0.002 & 21.86 & 0.0009 \\
\hline$x_{2}$-Time & 0.003 & 1 & 0.003 & 31.89 & 0.0002 \\
\hline$X_{3}$-solvent ratio & 0.11 & 1 & 0.11 & 1065.88 & $<0.0001$ \\
\hline$x_{1} x_{2}$ & 0.0006 & 1 & 0.0006 & 5.82 & 0.0365 \\
\hline$x_{1} x_{3}$ & 0.033 & 1 & 0.033 & 308.93 & $<0.0001$ \\
\hline$x_{2} x_{3}$ & 0.012 & 1 & 0.012 & 114.14 & $<0.0001$ \\
\hline$x_{1}^{2}$ & 0.044 & 1 & 0.044 & 421.70 & $<0.0001$ \\
\hline$x_{2}^{2}$ & 0.0006 & 1 & 0.0006 & 57.66 & $<0.0001$ \\
\hline$x_{3}^{2}$ & 0.0008 & 1 & 0.0008 & 8.25 & 0.0166 \\
\hline Residual & 0.001 & 10 & 0.0001 & & \\
\hline Lack of fit & 0.0005 & 5 & 0.0001 & 0.97 & 0.5115 \\
\hline Pure error & 0.0005 & 5 & 0.0001 & & \\
\hline Cor total & 0.22 & 19 & & & \\
\hline $\begin{array}{l}R^{2}=0.9952 \\
\text { Adj. } R^{2}=0.9909 \\
\text { CV\% }=0.17\end{array}$ & & & & & \\
\hline
\end{tabular}
intervals and this analysis was crucial to determine the best fitted quadratic model for three independent variables. A regression model was evaluated by using $F$ statistics and lack of fit test. Based on the results, it showed

Table 2 Analysis of variance (ANOVA) for the model 
that the model is highly significant when the computed $F$-value is greater than the tabulated $F$-value and the probability value is low $(p<0.0001)$ indicating that the individual terms in each response model were significant on the interaction effect.

The performance of the models was also checked by calculating the determination coefficients $R^{2}$, adjusted $R^{2}$, regression ( $p$ value), regression $(F$-value), lack of fit (p-value), coefficient variation (C.V\%) and probability values related to the effect of the three independent variables. Based on the result, the coefficient of determination $R^{2}$ is defined as the ratio of the explained variation to the total variation in total phenolic and total flavonoid contents were $R^{2}=0.9993$ and $R^{2}=0.9952$ respectively showing a good fit model. The closer $R^{2}$ value to unity, the better and significant empirical model fits the actual data. Furthermore, the calculated adjusted $R^{2}$ values for studied responses variables were higher than 0.80 , hence there is a close agreement between the experimental results and the theoretical values predicted by the proposed models. The coefficients of variations (C.V) for total phenolic and flavonoid contents were 0.24 and 0.17 respectively, which indicates that a relatively lower value of CV showed a better reliability of the response model. It was observed that the lack of fit gave no indication of significance $(p<0.05)$ for all the models tested, thus proving that the satisfactory fitness of the response surface model was within the chosen range and significant $(p<0.05)$ to the factors effect.

Based on analysis of ANOVA, any terms from quadratic polynomial coefficients model, large F-values and a small $p$-values indicated a more significant effect on the respective response variables. The 3-D surface plots of the fitted polynomial regression equations were generated by the software to better visualize the interaction effect of independent variables on responses.

\section{Response surface analysis}

Temperature, time and ethanol concentration are the main factors that affect the extraction condition of the maximum total phenolics and flavonoids content. This section discusses how these conditions work on natural antioxidants extraction. Three-dimensional model graphs were plotted as shown in the respective figures. The response surface plots of the model were done by varying two variables, within experimental range under investigation and holding the other variables at its central level (0 levels).

\section{Effects of process variables on the total phenolics content} (TP)

The amount of extracted phenolics content from Curcuma zedoaria leaves ranged from 98 to 135 sample extract, measured as gallic acid equivalent (GAE). The value of mean recorded was $120.04 \mathrm{mg} / \mathrm{g}$ GAE of total leaves extracts. The highest TP content was reported at experimental run no. 8 while the lowest TP content was observed at experimental run no. 13. The ANOVA showed the model $F$ value of 1662.76 with probability ( $\mathrm{p}<0.0001)$ which implies that the model is significant and there is only $0.01 \%$ chances that this large $F$ value could occur due to noise. Phenolic content was significantly influenced at $(\mathrm{p}<0.05)$ by all three linear $\left(X_{1}, X_{2}\right.$, $\left.X_{3}\right)$, interaction parameters $\left(X_{1} X_{2}, X_{1} X_{3}, X_{2} X_{3}\right)$ and quadratic parameters $\left(X_{1}^{2}, X_{2}^{2}, X_{3}^{2}\right)$ (Table 2). The effect of their variables and their interaction on the responses can be seen in Fig. 1a-c.

The surface plot in Fig. 1a demonstrates the function of temperature $\left(X_{1}\right)$ versus time $\left(X_{2}\right)$ effect on total phenolic contents at fixed ethanol concentration (80:20). It was observed that increasing the extraction temperature and time resulted in higher phenolic content in Curcuma zedoaria leaves. The maximum amount of phenolics can be achieved at the highest temperature of $75-80{ }^{\circ} \mathrm{C}$ at the shortest extraction time of $80-100 \mathrm{~min}$. Nevertheless, when the temperature was kept at the highest level of $80{ }^{\circ} \mathrm{C}$ with longer extraction time at $120 \mathrm{~min}$, they did not show any significant improvement in TP extraction as the value continuously dropped. This agreed with the working high temperature employed in this study which required short periods of time to avoid the degradation of the phenolic compounds. At short periods of time, the temperature enhanced the extraction process but for relatively long periods, the effect is inverted and the phenolic compounds are threatened by oxidation or degradation [17]. Moreover, according to Vajić et al. [18] prolonged time of extraction enhances phenolic solubility due to Fick's second law of diffusion which predicts that equilibrium of extraction will be achieved after a certain time. These results are similar to a study reported by of Rajha et al. [19] which showed the total phenolics from grape byproducts increased with the increment of temperature and reduction of time.

Figure $1 \mathrm{~b}$ depicts the effects of temperature $\left(X_{1}\right)$ versus ethanol concentration $\left(X_{3}\right)$ at constant extraction time $100 \mathrm{~min}$. The surface plot reveals that the maximum phenolic content can be achieved at highest ethanol concentrations (90:10) as compared with low ethanol concentrations (70:30) at fixed extraction temperature. The higher phenolic content could be explained by the natural polarity of the solvents used [20]. Ethanol and water were used in this study because they are safer to handle as compared to other organic solvents and more importantly, they are acceptable for human consumption. Samuagam et al. [21] stated that a suitable solvent ratio is able to improve the efficiency of extraction. The surface plots also reveal that by increasing the extraction 

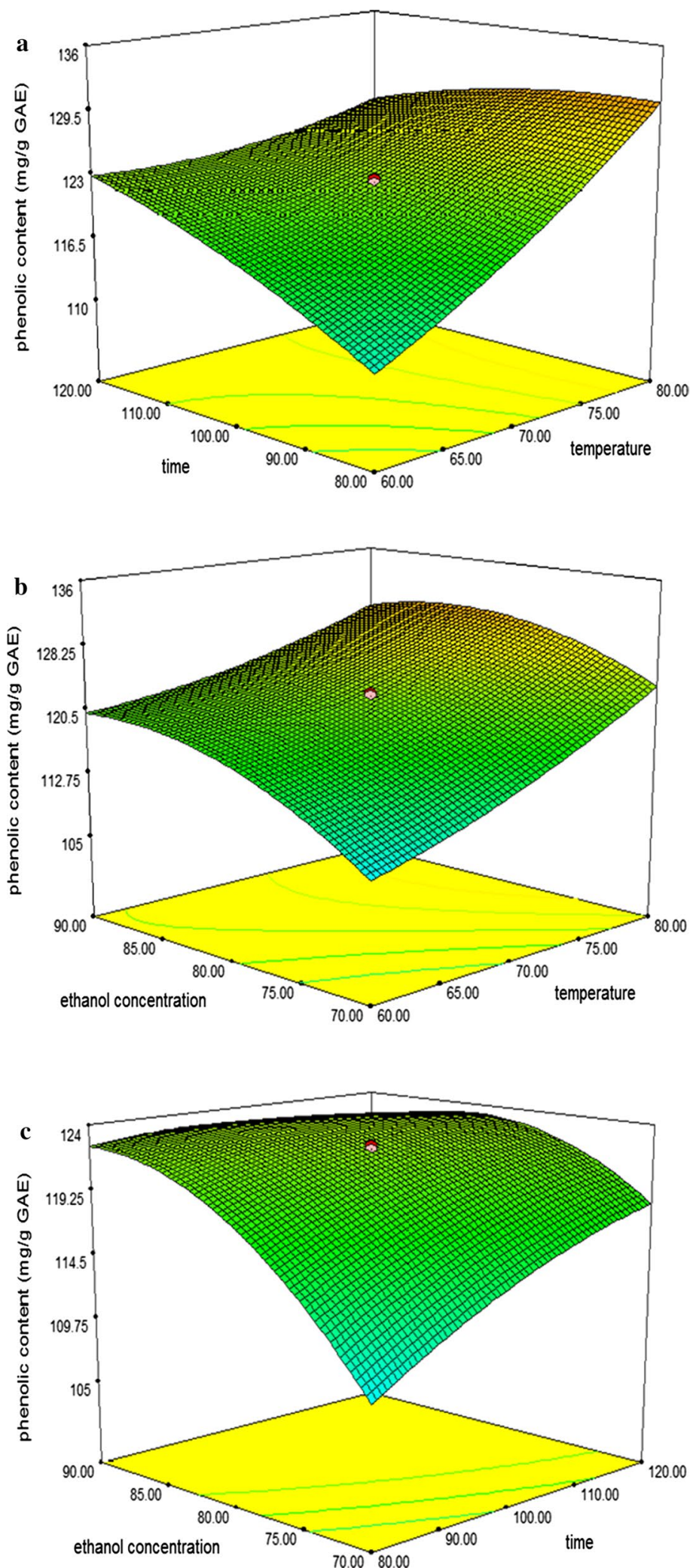

Fig. 1 Response surface plots for the effects of temperature, time and ethanol concentration on total phenolic contents of Curcuma zedoaria leaves extracts. a Temperature versus time. $\mathbf{b}$ Ethanol concentration versus temperature. c Time versus ethanol concentration 
temperature to higher levels, the amounts of phenolic gradually dropped and this might be explained by the fact that the final equilibrium between the solvent concentrations in the plant matrix and the temperature will be achieved after a certain concentration level [22]. This phenomenon is similar to a phenolic study from lettuce by-products which can be explained by the use of higher temperature and adequate solvent concentrations which may cause softening of plant tissue, resulting in enhanced diffusion rate and increase in the production of phenolic compounds. However, after a certain level, it will subsequently decline and remain constant as the extraction has completed and they have achieved their equilibrium state [23]. Therefore, the maximum total phenolic content in Curcuma zedoaria leaves can be obtained with optimum ethanol concentration and an extraction temperature of approximately $80-85 \mathrm{v} / \mathrm{v} \%$ and $75-80^{\circ} \mathrm{C}$ respectively.

The response surface plot as a function of time $\left(X_{2}\right)$ versus ethanol concentration $\left(X_{3}\right)$ at constant temperature $70{ }^{\circ} \mathrm{C}$ is presented in Fig. 1c. The surface plots revealed that the higher TP contents can be obtained when conducted at increasing ethanol concentration at fixed extraction time. Based on the result at constant extraction time of $120 \mathrm{~min}, 90 \%$ of ethanol concentrations yielded the most TP as compared with $70 \%$ ethanol concentrations. However, longer extraction time degrade the phenolic activity in Curcuma zedoaria leaves. Therefore the optimum extraction of phenolic can be obtained when conducted at a range of $80-90 \mathrm{v} / \mathrm{v} \%$ and $100 \mathrm{~min}$ of ethanol concentrations and extraction time respectively. Beyond this optimal, the TP content declined. These overall results of phenolic content indicate a similar trend as observed in the phenolic content of tea (camellia sinensis L.) fruit peel by Xu et al. [24] where the TP contents increased with increasing the independent variables ethanol concentration and processing time until a maximum amount of phenolic was reached, thereafter, the amount subsequently declined rapidly as reaction has completed.

\section{Effects of process variables on the total flavonoids content (TF)}

The mean experimental data showing the total flavonoid content from Curcuma zedoaria leaves at various extraction conditions was $6.20 \mathrm{mg} \mathrm{QE} / \mathrm{g}$ of extract in the total range of $6.00-6.38 \mathrm{mg} \mathrm{QE} / \mathrm{g}$ of extract. The highest content of TF was observed at experimental run no. 17 meanwhile the lowest yield of TF was observed in experimental run no 2. The ANOVA showed the model $F$ value of 229.66 with probability $(\mathrm{p}<0.0001)$ which implies that the model is significant and there is only $0.01 \%$ chances that this large $F$ value could occur due to noise. Flavonoids content was significantly influenced at $(\mathrm{p}<0.05)$ by all three linear $\left(X_{1}, X_{2}, X_{3}\right)$, interaction parameters
$\left(X_{1} X_{2}, X_{1} X_{3}, X_{2} X_{3}\right)$ and quadratic parameters $\left(X_{1}^{2}, X_{2}^{2}, X_{3}^{2}\right)$ (Table 2). The effect of their variables and their interaction on the responses can be seen in Fig. $2 \mathrm{a}-\mathrm{c}$.

The 3D shows the response surface plot as a function of temperature $\left(X_{1}\right)$ versus time $\left(X_{2}\right)$ at fixed extraction ethanol concentration (80:20) as shown in Fig. 2a. Response surface plot showed that extraction temperature exhibited a weaker effect whereas extraction time represented a relatively significant effect on the flavonoids yield. An increase in the yield of flavonoid could be significantly achieved with the increase of extraction time, at any level of extraction temperature. Therefore, the optimum amount of flavonoid was achieved in this study at $65-70{ }^{\circ} \mathrm{C}$ and $90-100 \mathrm{~min}$ of extraction time. However, the results of the present research for time and temperature were different compared with other studies $[4,19]$. This difference could be the due to differences in the type of material, considering some plants may synthesize and accumulate the different amount of secondary metabolites (flavonoids) and also the optimization extractions range used in the study.

The 3D surface plots in Fig. 2b shows the interaction between extraction temperature $\left(X_{1}\right)$ and ethanol concentration $\left(X_{3}\right)$ at the fixed $100 \mathrm{~min}$. Statistical analysis reveals that the most significant with $p<0.0001$ in TF was ethanol concentration. According to Bazykina et al. [25] flavonoids and their glycosides are thought to be efficiently extracted from plant materials by ethanol solvent. It was observed that the value of TF increased when ethanol concentration was increased from 70 to $90 \mathrm{v} / \mathrm{v} \%$ at fixed $60{ }^{\circ} \mathrm{C}$ extraction temperature. In contrast, increasing the extraction temperature at highest ethanol concentrations resulted to decreased, TF values. This phenomenon can be explained by the higher movement of the particles which causes plant tissue to rupture and hence allowing higher solubility of solvent until it starts to degrade to a lower value as it had achieved the stable state [26]. The results obtained for flavonoids are in agreement with the previous report from Cryptotaenia japonica hassk by Lu et al. [27] where the flavonoid content increased when the temperature of extraction increased to below $70{ }^{\circ} \mathrm{C}$ and exhibited a decreasing trend above the optimum level of temperature. Thus, as mentioned earlier the optimum extraction temperature for maximum flavonoid content was at $65-70{ }^{\circ} \mathrm{C}$ with $85-90 \mathrm{v} / \mathrm{v} \%$ ethanol concentrations.

Figure 2c illustrates the response surface plot between the extraction time $\left(X_{2}\right)$ and ethanol concentration $\left(X_{3}\right)$ at constant extraction temperature $\left(70{ }^{\circ} \mathrm{C}\right)$. The response surface plots demonstrated that the value of TF obtained in Curcuma zedoaria leaves mainly depended upon ethanol concentrations. An increase in ethanol concentration promoted the breakdown of the cell membrane 

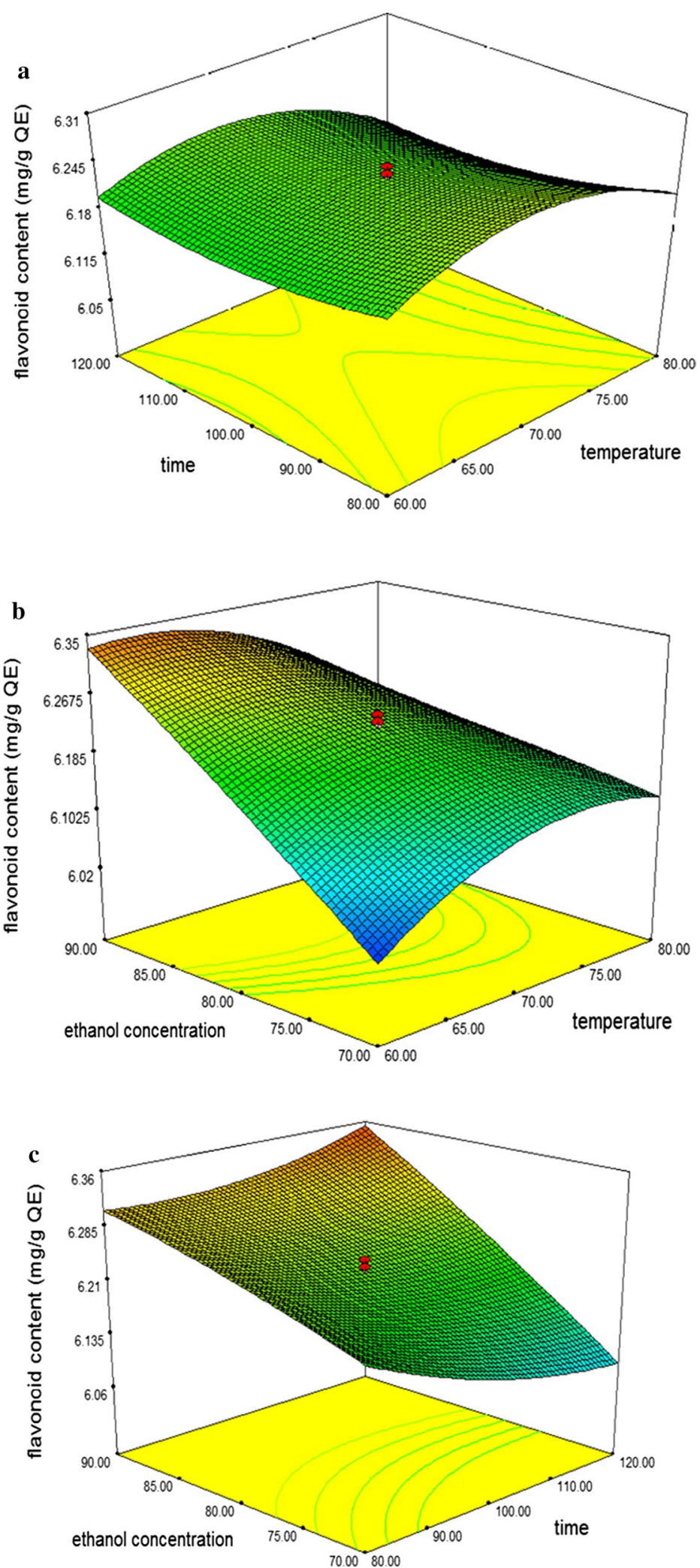

Fig. 2 Response surface plots for the effects of temperature, time and ethanol concentration on total flavonoid content of Curcuma zedoaria leaves extracts. a Temperature versus time. $\mathbf{b}$ Ethanol concentration versus temperature. c Time versus ethanol concentration 
that enhanced the permeability of the solvent into a solid matrix. In this study, highest flavonoids content can be achieved when conducted at highest ethanol to water ratio (90:10) as compared with (70:30) with increasing extraction time. A great increase in the yield also resulted when extraction time was increased in the range of 80-120 min. However, the time curve started to level off at $100 \mathrm{~min}$, which indicated that $100 \mathrm{~min}$ were required to achieve maximum flavonoids activity.

\section{Optimization of extracting parameters and validation of the model}

In this study, the aim was to find the conditions which gave the maximum yield of total phenolic and flavonoids content. The final result for the simultaneous optimization using the desirability function approach suggested that the optimal ethanolic extraction conditions for Curcuma zedoaria leaves extract were at $75{ }^{\circ} \mathrm{C}$ with $92 \mathrm{~min}$ and 90:10 of ethanol concentration to achieve the best combination for highest total phenolic and flavonoids content. These optimum extraction conditions were evaluated by considering the simultaneous response surface and contour plot from the interaction between the independent variables and responses of interest. In order to verify the optimum conditions, the Curcuma zedoaria leaves were subjected using the optimal conditions above and the results were statistically compared to the predicted values given by the design expert 7.0.0 software of the response surface methodological (RSM) model. Based on the results, the predicted values of responses were found to be quite comparable with experimental values at 95\% confidence level in Table 3.

\section{Conclusions}

Response surface methodology (RSM) and a design called central composite design (CCD) were successfully developed to determine the optimum process parameters and the second order polynomial models for predicting responses were obtained. The best combination of extraction temperature, time and ethanol concentrations were found to be $75{ }^{\circ} \mathrm{C}$ with $92 \mathrm{~min}$ and 90:10 ethanol to water ratio which rendered a mean phenolic content

Table 3 Comparison between the predicted and experimental values for antioxidants from extracts of Curcuma zedoaria leaves

\begin{tabular}{lll}
\hline Condition & \multicolumn{2}{l}{ Response values } \\
\cline { 2 - 3 } & $\begin{array}{l}\text { Phenolic content } \\
\mathbf{m g} / \mathbf{g} \text { GAE }\end{array}$ & $\begin{array}{l}\text { Flavonoid content } \\
\mathbf{m g} / \mathbf{g} \text { QE }\end{array}$ \\
\hline Predicted & 126.25 & 6.24 \\
Experimental & $125.75 \pm 0.17$ & $6.12 \pm 0.23$
\end{tabular}

of $125.75 \pm 0.17 \mathrm{mg} / \mathrm{g}$ GAE and $6.12 \pm 0.23 \mathrm{mg} / \mathrm{g}$ QE of total flavonoid content from experimental run and thus indicated good antioxidant activities from the leaves of Curcuma zedoaria.

\section{Materials and methods}

\section{Raw materials}

Curcuma zedoaria leaves were collected from a local farmer in Kedah, Malaysia. The chemicals, sodium carbonate, aluminium chloride, ethanol was purchased from J. Kollin Chemicals, Germany. Folin-Ciocalteu's phenol reagent, gallic acid and quercetin were purchased from Sigma-Aldrich (St. Louis, MO, USA). All other chemical reagents used in this study were of analytical grade class.

\section{Plant extraction}

The air-dried leaves of Curcuma zedoaria plant were cut into pieces and ground into powder form using a mechanical blender. About $0.5 \mathrm{~g}$ of powdered leaves were exactly weighed into a $150 \mathrm{~mL}$ round bottomed flask and mixed with ethanol. The extraction process was performed using a reflux systems equipped with a temperature controller and digital timer. The extract was then filtered through normal filtration using Whatman filter paper and vacuum-dried in a rotary evaporator, at $40{ }^{\circ} \mathrm{C}$ until the excess solvent was completely removed.

\section{Experimental design}

The optimization of the extraction conditions from the Curcuma zedoaria leaves was established by using response surface methodology (RSM). This powerful mathematical and statistical technique is useful for modeling and analysis of problems in which a response is influenced by several independent variables and the objective is to find the relationship between the factor and the response to optimize the conditions. A design expert software Version 7.0.0, (Stat ease Inc., Minneapolis, USA) was used in this study. The experimental plan was carried out based on three factor/five level design referred to as rotatable central composite design (CCD). The selection of CCD as the experimental design is because it is more precise for estimating factor effects [28]. Hence, the interaction effect between factors can be evaluated and optimized in the full factor space.

The design consisted of twenty experimental runs, including six replicates at the center points. The center points were utilized to define the experimental error and the reproducibility of the data. The independent variables in this study were extraction temperature $\left(X_{1}: 60-80^{\circ} \mathrm{C}\right)$, time $\left(X_{2}: 80-120 \mathrm{~min}\right)$ and ethanol concentrations $\left(X_{3}\right.$ : $70-90 \% \mathrm{v} / \mathrm{v}$ ethanol/water). The five levels of values for the independent variables were explicit of their coded and uncoded forms in Table 4. The value of independent 
variables was expressed in their coded values as $-1,0$, +1 interval shows the low, center, and high level of each variable, respectively. The multiple regression analysis was performed on the data of response variables such as total phenols and flavonoid content obtained as affected by the extraction conditions and was fitted into a polynomial regression equation as shown in the following equations (Eq. 3);

$$
Y=\beta_{o}+\sum_{i=1}^{k} \beta_{i} X_{i}+\sum_{i=1}^{k} \beta_{i i} X_{i}^{2}+\sum_{i=1}^{k} \sum_{j i}^{k} \beta_{i j} X_{i} X_{j}+e
$$

where $Y$ represents the response variables to be modeled; $\beta_{o}$ is a constant, $\beta_{\mathrm{i}}, \beta_{\mathrm{ii}}$ and $\beta_{\mathrm{ij}}$ are the linear, quadratic and cross-product coefficients, respectively. $X_{i}$ and $X_{j}$ are the levels of the independent variables. $k$ is the number of variables and $e$ is the random error of the model.

\section{Determination of total phenolic content}

The total phenolic compounds in Curcuma zedoaria leaves was developed using the method of Singleton and Rossi [29] with minor modifications. For each sample, $100 \mu \mathrm{L}(1 \mathrm{mg} / \mathrm{mL})$ of the sample extract was mixed with $50 \mu \mathrm{L}$ Folin-Ciocalteu's reagent $(2 \mathrm{~N})$ previously diluted with $7.9 \mathrm{~mL}$ distilled water. After $4 \mathrm{~min}, 1.5 \mathrm{~mL}$ of 7.5 $\mathrm{w} / \mathrm{v} \%$ sodium carbonate solution was added to the mixture and incubated in the dark room at room temperature for $2 \mathrm{~h}$. The absorbance values of the sample were measured at $765 \mathrm{~nm}$ using a UV-VIS microplate reader. Standard of gallic acid with different concentrations $(25-1000 \mu \mathrm{g} / \mathrm{L})$ was prepared in this study to generate a standard calibration curve. The samples were calculated based on the standard calibration curve and were expressed as mg gallic acid equivalent (mg/g GAE).

\section{Determination total flavonoids content}

The content of flavonoid in the studied leaves extract was determined using spectrophotometric method [30]. From each sample, $100 \mu \mathrm{L}(1 \mathrm{mg} / \mathrm{mL})$ were mixed with $2 \% \mathrm{AlCl}_{3}$ and incubated for $15 \mathrm{~min}$ at room temperature.
The absorbance was measured at $\lambda=406 \mathrm{~nm}$. The same procedure was repeated for the standard solution of quercetin at different concentrations $(25-250 \mu \mathrm{g} /$ $\mathrm{mL}$ ) and the calibration line was obtained. Based on the measured absorbance, the concentration of flavonoids was calculate $(\mathrm{mg} / \mathrm{mL})$ on the calibration line and the content of flavonoids in extracts was expressed in terms of quercetin equivalent, $\mathrm{QE}$ (mg of quercetin/g of extract).

\section{Statistical analysis and optimization}

Best fitted model of response can be achieved by highlighting these statistical parameters including the adjusted multiple correlation coefficients (adjusted $R^{2}$ ), multiple correlation coefficients $\left(R^{2}\right)$, coefficient variation (C.V\%), lack of fit, regression F-value and regression $p$-value by using analysis of variance (ANOVA). This statistical approach was used to summarize the results obtained under all experimental conditions with a confidence interval of $95 \%$ set to test the significant effect of the factors and their interaction. The optimal extraction conditions were selected based on the condition of achieving the highest total phenolics and flavonoids content in Curcuma zedoaria leaves by using the desirability function approach in design expert software. The fitted polynomial equation was expressed in the form of three-dimensional surface plots in order to illustrate the relationship between responses and the experimental variables used.

\section{Verification of models}

The optimal conditions for the extraction of the total phenolic and flavonoid content from Curcuma zedoaria leaves, in terms of extraction temperature, time and ethanol concentrations, were determined by comparing the actual experimental values with predicted value from the final response regression equations. Besides, a few random extraction conditions were prepared in order to validate the models. This action is of utmost importance to confirm the adequacy of the final reduced models.

Table 4 Independent test variables and their coded and uncoded value used for CCD matrix

\begin{tabular}{|c|c|c|c|c|c|c|}
\hline \multirow[t]{2}{*}{ Variables } & \multirow[t]{2}{*}{ Units } & \multicolumn{5}{|c|}{ Coded \& uncoded level of variables } \\
\hline & & $-a$ & -1 & 0 & 1 & $+a$ \\
\hline Temperature, $X_{1}$ & ${ }^{\circ} \mathrm{C}$ & 53 & 60 & 70 & 80 & 87 \\
\hline Time, $X_{2}$ & Min & 66 & 80 & 100 & 120 & 133 \\
\hline $\begin{array}{l}\text { Solvent ratio, } X_{3} \\
\text { Ethanol:water }\end{array}$ & $\mathrm{v} / \mathrm{v} \%$ & 63 & 70 & 80 & 90 & 97 \\
\hline
\end{tabular}




\section{Authors' contributions}

NFA participated in the design of the study and performed the statistical analysis. SSAG and NFMM participated in the sequence alignment and drafted the manuscript. All authors read and approved the final manuscript.

\section{Author details}

${ }^{1}$ Department of Agriculture Technology, Faculty of Agriculture, Universiti Putra Malaysia (UPM), 43400 Serdang, Selangor, Malaysia. ${ }^{2}$ Halal Products Research Institute, Universiti Putra Malaysia (UPM), 43400 Serdang, Selangor, Malaysia.

${ }^{3}$ Institute for Mathematical Research (INSPEM), Universiti Putra Malaysia (UPM), 43400 Serdang, Selangor, Malaysia.

\section{Acknowledgements}

The authors gratefully acknowledge the financial support from a Graduate Research Fellowship (GRF) under UPM for the scholarship.

\section{Competing interests}

The authors declare that they have no competing interests.

\section{Publisher's Note}

Springer Nature remains neutral with regard to jurisdictional claims in published maps and institutional affiliations.

Received: 24 August 2016 Accepted: 21 September 2017 Published online: 02 October 2017

\section{References}

1. Ghasemzadeh A, Jaafar HZE, Rahmat A (2010) Antioxidant activities, total phenolics and flavonoids content in two varieties of malaysia young ginger (Zingiber officinale Roscoe). Molecules 15:4324-4333

2. Karabegović IT, Stojičević SS, Veličković DT, Todorović ZB, Nikolić NČ, Lazić ML (2014) The effect of different extraction techniques on the composition and antioxidant activity of cherry laurel (Prunus laurocerasus) leaf and fruit extracts. Ind Crops Prod 54:142-148

3. Heydari Majd M, Rajaei A, Salar Bashi D, Mortazavi SA, Bolourian S (2014) Optimization of ultrasonic-assisted extraction of phenolic compounds from bovine pennyroyal (Phlomidoschema parviflorum) leaves using response surface methodology. Ind Crops Prod 57:195-202

4. Sheng ZL, Wan PF, Dong CL, Li YH (2013) Optimization of total flavonoids content extracted from Flos Populi using response surface methodology. Ind Crops Prod 43:778-786

5. Liu Y, Wei S, Liao M (2013) Optimization of ultrasonic extraction of phenolic compounds from Euryale ferox seed shells using response surface methodology. Ind Crops Prod 49:837-843

6. Huo L, Lu R, Li P, Liao Y, Chen R (2011) Antioxidant activity, total phenolic and total flavonoid of extracts from the stems of Jasminum nervosum Lour. Grasas Aceites 2:149-154

7. Kalita P, Barman TK, Pal TK, Kalita R (2013) Estimation of total flavonoids content (TFC) and antioxidant activities of methanolic whole plant extract of biophytum sensitivum linn. J drug deliv Ther 4:33-37

8. Lobo R, Prabhu KS, Shirwaikar A, Shirwaikar A (2009) Curcuma zedoaria Rosc. (white turmeric): a review of its chemical, pharmacological and ethnomedicinal properties. J Pharm Pharmacol 61:13-21

9. Tholkappiyavathi K, Selvan KM, Neyanila SK, Yoganandam GP, Gopal V (2013) A concise review on Curcuma Zedoaria. Int J Phyther 2:1-4

10. Srivastiva NR, Lal BR, Kumar SV, Dhirendra K (2013) Physicochemical and phytochemical investigation of three different species of Curcuma rhizome. Int Res J Pharm 4:163-166

11. Anisuzzaman M, Sharmin SA, Mondal SC, Sultana R, Khalekuzzaman M (2008) In vitro microrhizome induction in Curcuma zedoaria (christm.) roscoe-a conversation prioritized medicinal plant. J Biol Sci 8:1216-1220
12. Angel GR, Vimala B, Nambisan B (2012) Phenolic content and antioxidant activity in five underutilized starchy Curcuma species. Int J Pharmacogn Phytochem Res 4:69-73

13. Srivastava S, Mehrotra S, Rawat A (2011) Pharmacognostic evaluation of the rhizomes of Curcuma zedoaria Rosc. Pharmacogn J 3:18-24

14. Himaja M, Ranjitha A, Ramana MV, Anand M, Asif K (2010) Phytochemical screening and antioxidant activity of rhizome part of Curcuma Zedoaria. Int J Res Ayurveda Pharm 1:414-417

15. Aybastier O, Isik E, Sahin S, Demir C (2013) Optimization of ultrasonicassisted extraction of antioxidant compounds from blackberry leaves using response surface methodology. Ind Crop Prods 44:558-565

16. Chanda SV, Nagani KV (2010) Antioxidant capacity of Manilkara zapota L. leaves extracts evaluated by four in vitro methods. Nat Sci 8:260-266

17. Yilmaz Y, Toledo RT (2006) Oxygen radical absorbance capacities of grape/wine industry byproducts and effect of solvent type on extraction of grape seed polyphenols. J Food Compos Anal 19:41-48

18. Vajić UJ, Grujić-Milanović J, Živković J, Šavikin K, Gođevac D, Miloradović Z, Bugarski B, Mihailović-Stanojević N (2015) Optimization of extraction of stinging nettle leaf phenolic compounds using response surface methodology. Ind Crops Prod 74:912-917

19. Rajha HN, Darra NE, Hobaika Z, Boussetta N, Vorobiev E, Maraoun RG, Louka N (2014) Extraction of total phenolic compound, flavonoids, anthocyanins, and tannis from grape byproducts by response surface methodology. Influence of solid-liquid ratio, particle size, time, temperature and solvent mixtures on the optimization process. Food Nutr Sci 5:397-409

20. Tan MC, Tan CP, Ho CW (2013) Effects of extraction solvent system, time and temperature on total phenolic content of henna (Lawsonia inermis) stems. Int Food Res J 20:3117-3123

21. Samuagam L, Sia CM, Akowuah GA, Okechukwu PN, Yim HS (2013) The effect of extraction conditions on total phenolic content and free radical scavenging capacity of selected tropical fruits' peel. Heal Environ J 4:80-102

22. Sai-Ut S, Benjakul S, Kraithong S, Rawdkuen S (2015) Optimization of antioxidants and tyrosinase inhibitory activity in mango peels using response surface methodology. LWT Food Sci Technol 64:742-749

23. Gomes T, Delgado T, Ferreira A, Pereira JA, Baptista P, Casal S, Ramalhosa E (2013) Application of response surface methodology for obtaining lettuce (Lactuca sativa L.) by-products extracts with high antioxidative properties. Ind Crops Prod 44:622-629

24. Xu P, Bao J, Gao J, Zhou T, Wang Y (2012) Optimization of extraction of phenolic antioxidants from tea (camellia sinensis L.) fruit peel biomass using response surface methodology. BioResources 2:2431-2443

25. Bazykina NI, Nikolaevskii AN, Filippenko TA, Kolerva VG (2002) Optimization of conditions for the extraction of natural antioxidants from raw plant materials. Pharm Chem J 36:46-49

26. Yoswathana N (2013) Optimization of ScCO2 extraction of rambutan seed oil using response surface methodology. Int J Chem Eng Appl 4:187-190

27. Lu J, Zhou C, Rong O, Xu Y (2013) Optimization of microwave-assisted extraction of flavonoids from Cryptotaenia japonica hassk using response surface methodology. Adv J food Sci Technol 5:310-317

28. Mohd Taib SH, Abd Gani SS, Ab Rahman MZ, Basri M, Ismail A, Shamsudin $R$ (2015) Formulation and process optimizations of nano-cosmeceuticals containing purified swiftlet nest. RSC Adv 5:42322-42328

29. Singleton VL, Rossi JA (1965) Colorimetry of total phenolics with phosphomolybdic-phosphotungstic acid reagent. Am J Enol Vitic 16:144-153

30. Stankovic M (2011) Total phenolic content, flavonoid concentration and antioxidant activity of Marrubium peregrinum L. extracts. Kragujevac J Sci 33:63-72 